\title{
КОМПЛЕКСНЫЕ РЕШЕНИЯ ПО ПОВЫШЕНИЮ ЭФФЕКТИВНОСТИ РАЗРАБОТКИ МНОГОПЛАСТОВЫХ ГАЗОВЫХ И ГАЗОКОНДЕНСАТНЫХ МЕСТОРОЖДЕНИЙ
}

\section{Пономарёв Александр Иосифович',} pnmrv@mail.ru

\section{Ситдиков Рустам Фадисович ${ }^{2}$,} SitdikovRF@kchn.ru

Ибатулин Артур Адикович $4^{13}$, AAlbatulin@purneftegaz.ru

\section{Федоров Алексей Эдуардович4,3,} AEFedorov@purneftegaz.ru

\author{
Муслимов Булат Шамильевич5 \\ MuslimovBS@ufanipi.ru \\ 1 Уфимский государственный нефтяной технический университет, \\ Россия, 450062, г.Уфа, ул. Космонавтов, 1. \\ 2000 «Харампурнефтегаз», \\ Россия, 629830, г. Губкинский, территория панель 1, 3. \\ 3000 «РН-Пурнефтегаз», \\ Россия, 629830, г. Губкинский, микрорайон 10, 3. \\ ${ }^{4}$ Российский государственный университет нефти и газа \\ (национальный исследовательский университет) им. И.М. Губкина, \\ Россия, 119991, г. Москва, пр. Ленинский, 65, корп. 1 \\ ${ }^{5} \mathrm{OOO} «$ «Н-УфанИПИнефть», \\ Россия, 450103, г. Уфа, ул. Сочинская, 12
}

Актуальность. С целью снижения капитальных затрат и сокращения времени выработки запасов газа и конденсата многопластового газоконденсатного месторождения актуальной задачей является обоснование технологии одновременной разработки различных по ресурсно-энергетическому потенциалу и/или фильтрационно-емкостным свойствам эксплуатационных объектов с подачей газа в одну газосборную сеть. Решение этой задачи актуально как на стадии проектирования, так и в зрелой стадии разработки месторождения на режиме истощения пластовой энергии. В условиях резкого различия ресурсно-энергетического потенциала и фильтрационно-емкостных свойств разрабатываемых объектов низконапорные скважины при определенном противодавлении в системе сбора газа прекращают фонтанирование и переводятся в бездействующий фонд до снижения линейного давления к необходимому уровню.

Цель: обоснование комплексных технологических решений, направленных на повышение эффективности разработки многопластовых газовых и газоконденсатных месторождений с единой газосборной сетью.

Объекты: многопластовые газовые и газоконденсатные месторождения, содержащие в геологическом разрезе разобщенные и различные по ресурсно-энергетическому потенциалу и фильтрационно-емкостным свойствам выделенные эксплуатационные объекты.

Методы: анализ текущего состояния разработки газовых эксплуатационных объектов Губкинского месторождения, аналитические расчеты технологических режимов работы низконапорных скважин, проведение опытно-промышленных испытаний на газовых скважинах Губкинского месторождения, технико-экономический анализ результатов применения предложенных технологий.

Результаты. Произведен анализ текущего состояния Губкинского месторождения, характеризуемого высокой дифференциацией текущих пластовых давлений по продуктивным пластам. Предложены комплексные решения по обеспечению совместной разработки эксплуатационных объектов с подачей газа в общую газосборную сеть, обеспечивающие устойчивые режимы работы скважин и основанные на регулировании устьевого давления различными техническими устройствами. Произведена технико-экономическая оценка влияния представленных комплексных технологических решений на эффективность разработки нижнемеловых пластов Губкинского месторождения.

\section{Ключевые слова:}

Разработка многопластовых газовых месторождений, модульные компрессорные установки, газоструйные аппараты, многопластовые залежи, опытно-промышленные испытания. 


\section{Введение}

На технико-экономическую эффективность разработки многопластовых газовых и газоконденсатных месторождений с различными ресурсноэнергетическими потенциалами и/или фильтрационно-емкостными свойствами (ФЕС) продуктивных пластов решающее влияние оказывают обоснование системы разработки и системы поверхностного обустройства.

В случаях нескольких эксплуатационных объектов разработки вариант разбуривания каждого объекта самостоятельной сеткой скважин и проектирование раздельной газопроводной сети является, как правило, наименее рентабельным либо нерентабельным ввиду больших капиталовложений. Чаще предпочтительным оказывается вариант поверхностного обустройства с общей газосборной сетью и реализацией стратегии поэтапного ввода в разработку объектов. В зависимости от ресурсно-энергетического потенциала, составов газа, геолого-физических характеристик и других параметров рассматриваются различные системы разработки [1-5 и др.].

Среди представленных стратегий поэтапного ввода в разработку объектов стоит отметить способ, согласно которому промышленное освоение месторождения начинают с нижних залежей газа, имеющих более высокое начальное пластовое давление, а вышезалегающие залежи вводят в эксплуатацию, когда текущее устьевое давление скважин, дренирующих нижние залежи, снизится до начального устьевого давления скважин, дренирующих вышезалегающие залежи $[1,5]$. Реализация данного способа возможна в условиях отсутствия ограничивающих критериев, связанных с различием состава газа групп пластов, их коллекторских и прочностных свойств. Достоинством способа является возможность совместной эксплуатации объектов с общей газосборной (трубопроводной) сетью. Стоит также отметить, что в процессе бурения на нижние горизонты возможно уточнение геологического строения и испытание транзитных объектов, что позволит снять риски, связанные с рентабельностью долгосрочных инвестиций.

Очевидным недостатком данного способа является увеличение срока разработки месторождения в связи с отложенным вводом в эксплуатацию вышележащих объектов и, как следствие, снижение уровней добычи газа и экономической эффективности реализации проекта в целом.

При совместной сетке скважин регулирование процесса отбора запасов отдельно по каждому пласту возможно осуществить с помощью технологии одновременно-раздельной эксплуатации объектов (ОРЭ). Такая технология в основном применяется на нефтяных месторождениях, ряд работ [6-10] посвящен анализу вариантов ее применения на газовых месторождениях. ОРЭ применяется с целью снижения затрат на сооружение скважин, однако усложнение конструкции скважин также приводит к существенному росту эксплуатационных затрат [6], что в долгосрочной перспективе может не привести к увеличению рентабельности проекта в целом. Кроме того, одной скважиной эксплуатируют в большинстве случаев только два пласта, эксплуатация более трех пластов практически не применяется.

В связи с необходимостью снижения капитальных затрат и сокращения времени выработки запасов актуальной задачей для многопластовых месторождений является создание способа одновременной разработки различных по ресурсно-энергетическому потенциалу и/или ФЕС эксплуатационных объектов многопластового газового месторождения с общей газосборной сетью.

Некоторые особенности разработки газовых и газоконденсатных объектов Губкинского месторождения

Решение задачи повышения технико-экономических показателей актуально не только на стадии проектирования, но и в процессе разработки многопластового месторождения. Рассмотрим текущее состояние разработки газовых объектов Губкинского месторождения, геологический разрез которого представлен на рис. 1.

Согласно проектной документации, выработку запасов свободного газа Губкинского месторождения было запланировано осуществлять поэтапно, начиная с нижних эксплуатационных объектов. По достижении проектных коэффициентов газоотдачи по нижним объектам планировалось введение в эксплуатацию верхних объектов. В процессе разработки для поддержания рентабельных уровней добычи и обеспечения необходимой загрузки поверхностного технологического оборудования был произведен частичный опережающий ввод в разработку верхних объектов.

Вследствие ввода новых скважин увеличение добычи газа приводит к росту линейного давления в газосборной сети. В условиях значительного различия ресурсно-энергетического потенциала и ФЕС объектов разработки низконапорные скважины нижних пластов ухудшенными продуктивными характеристиками при определенном противодавлении в системе сбора прекращают фонтанирование и переводятся в бездействующий фонд. В процессе дальнейшей разработки месторождения часть таких скважин может быть введена в эксплуатация при условии снижения линейного давления в газосборной сети (шлейфах и коллектоpax) до требуемого значения. Бездействие скважин приводит к неравномерной выработке запасов продуктивных пластов и ухудшению показателей разработки месторождения.

Для извлечения остаточных запасов из залежей, эксплуатация скважин которых ограничена термодинамическими условиями запроектированной инфраструктуры, необходима разработка новых технологических решений. 


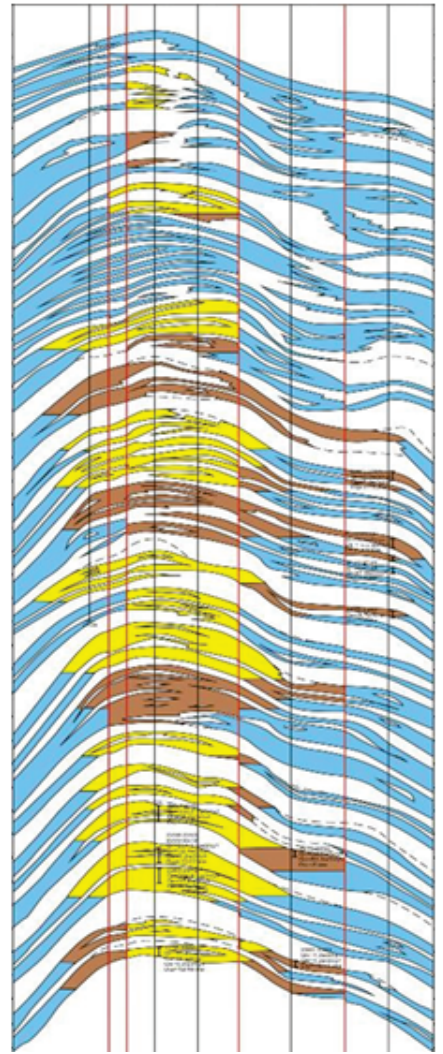

Пластовые давления:

БП ${ }^{1}-20,0$ МПа

БП $3-20,5 / 10,7$ МПа

БП ${ }_{5}{ }^{2}-21,0$ МПа

БП ${ }_{5}^{2}-21,1$ МПа

БП ${ }^{2}-21,4 / 9,7 \mathrm{M \Pi а}$

$\mathrm{БП}_{7}{ }^{1}-21,9 / 7,1 \mathrm{MПа}$

БП ${ }_{8}{ }^{0}-22,2 / 20,7 \mathrm{M \Pi а}$

$\mathrm{Б \Pi}_{8}{ }^{1}-22,4 / 11,9 \mathrm{M \Pi а}$

БП ${ }_{8}{ }^{2}-22,7 / 9,3$ МПа

БП $_{8}^{4}-22,7$ МПа

БП ${ }_{11}{ }^{1}-24,0 \mathrm{M \Pi а}$

Pис. 1. Разрез Губкинского многопластового месторождения

Fig. 1. Geological section of the Gubkinsky multilayer deposit

Разработка способов повышения эффективности добычи газа на многопластовых газовых месторождениях

Для повышения эффективности добычи газа и конденсата на многопластовых газовых и газоконденсатных месторождений и решения поставленной выше задачи предложен комплексный подход, включающий в себя ряд технических способов, обеспечивающих совместную разработку различных по энергетическому потенциалу и ФЕС эксплуатационных объектов при работе скважин в общую газосборную сеть. Предлагаемые решения основаны на регулировании давления на устье газовых скважин разных объектов с помощью различных технических устройств.

Для одновременной выработки запасов высокопотенциальных и низкопотенциальных объектов предлагается способ разработки многопластовых газовых месторождений, который реализуется следующим образом (рис. 2): разработка залежей/эксплуатационных объектов месторождения осуществляется самостоятельной сеткой добывающих скважин - 1, 2, 3 по каждому объекту, обустроенных общей газосборной сетью - 4. Разработка объектов осуществляется одновременно. $\mathrm{Pe}$ гулирование технологических режимов скважин, вскрывших пласты с пониженным ресурсно-энергетическим потенциалом, осуществляется подачей пластового газа с пластовыми примесями на установленную на устье скважин модульную компрессорную установку (МКУ), где реализуется отделение газа от механических примесей и воды. На МКУ производится компримирование газа до необходимого рабочего давления и последующая его подача в общую газосборную сеть (коллектор), где потоки смешиваются и газ по общему коллектору поступает на объекты подготовки скважинной продукции газового промысла (ГП).

При реализации разработанного способа для достижения указанного технического результата предложено использовать известное [11-16] устройство МКУ, которое представляет собой входной сепаратор и блок поршневого компрессора с приводом компрессора и переключающей арматурой.

В качестве примера конкретной реализации рассмотрим перспективы применения способа при проектировании технологической схемы разработки газовых объектов Харампурского месторождения, на котором выделено три газонасыщенных пласта: ПК1, Т, K2 - различных по ресурсно-энергетическому потенциалу и фильтрационно-емкостным свойствам. Основные запасы газа сосредоточены в объектах ПК1 и Т. Пласт ПК1 характеризуется высокой проницаемостью и приурочен к относительно неплотным породам, способным раз-

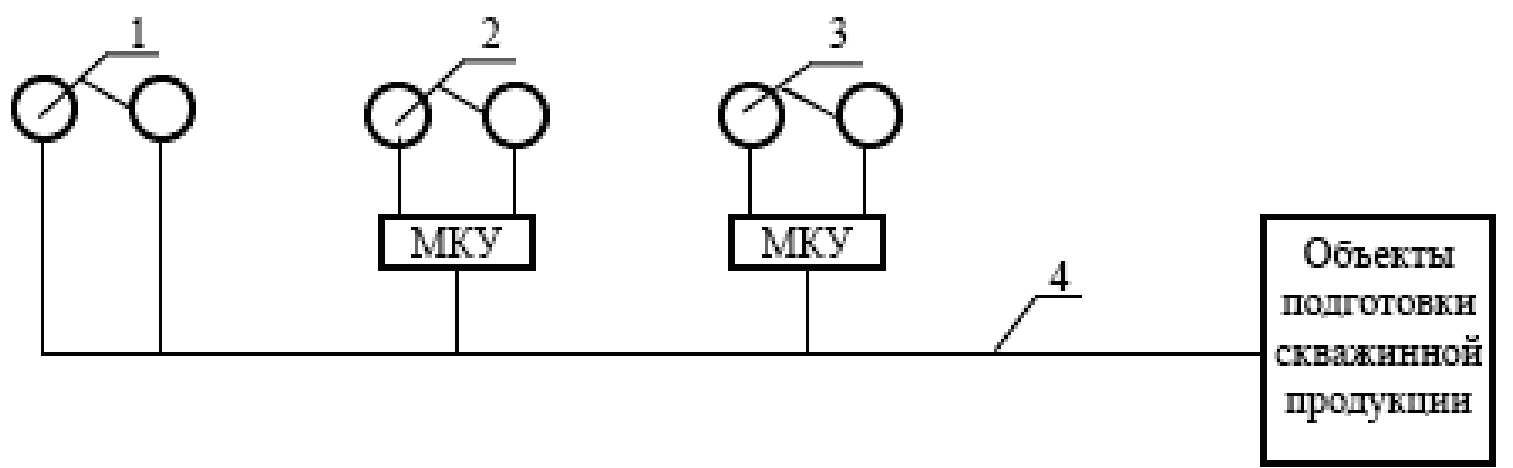

Рис. 2. Принципиальная схема подключения скважин кединой трубопроводной сети

Fig. 2. Schematic diagram of connecting wells to a single pipeline network 


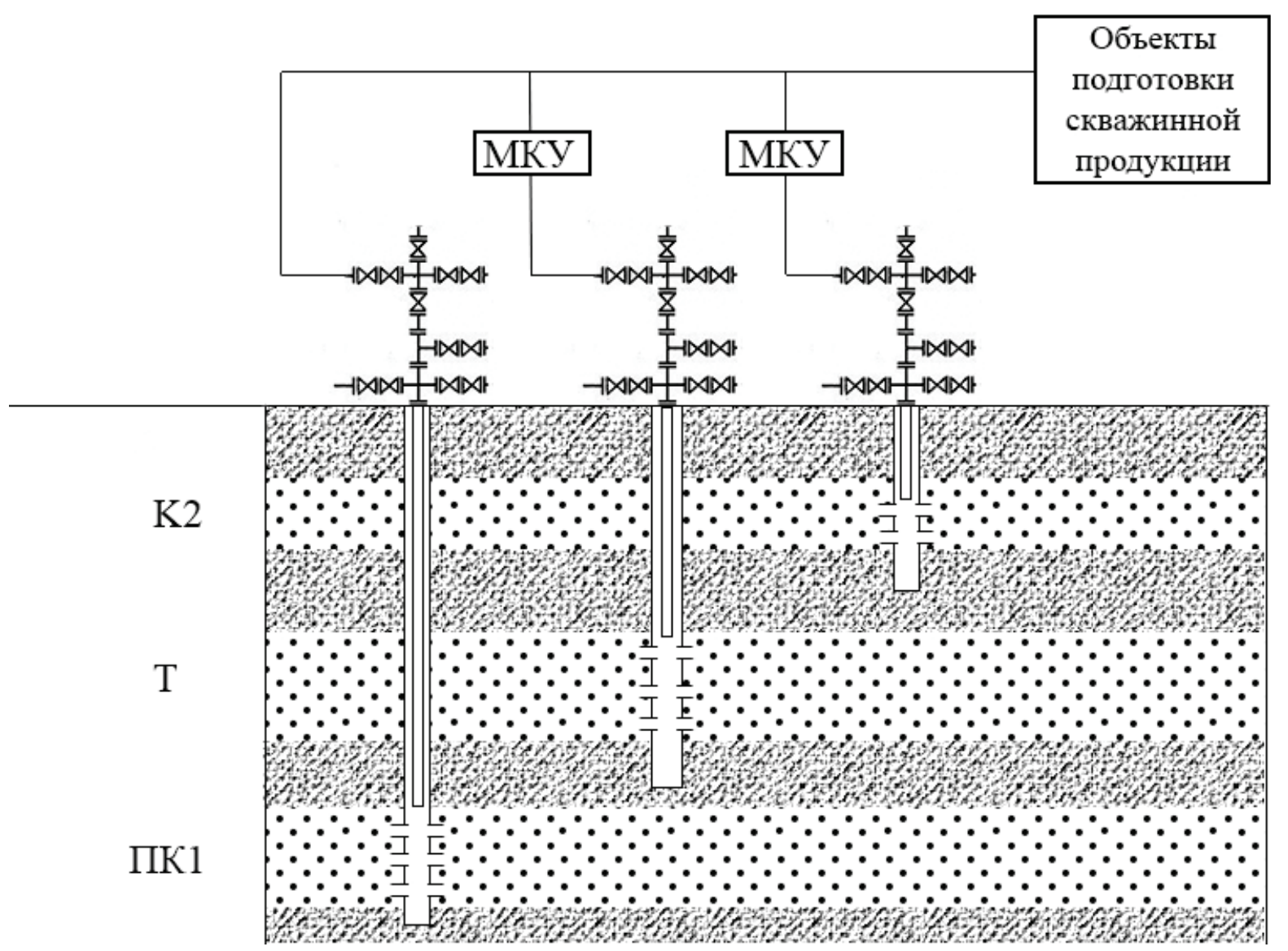

Рис. 3. Схема подключения скважин разных эксплуатационных объектов/пластов к единой трубопроводной сети Харалпурского нефтегазоконденсатного месторождения

Fig. 3. Scheme of connecting wells of different operational objects to a single pipeline network of the Kharampursky oil and gas condensate field

рушаться при нарушении установленных технологических режимов. Ввиду низких фильтрационноемкостных свойств для обеспечения устойчивых технологических режимов работы скважин, вскрывших пласт Т и К2, требуются относительно высокие депрессии. С учетом особенностей месторождения предложен вариант подключения скважин разных эксплуатационных объектов/пластов $\kappa$ единой газосборной сети Харампурского нефтегазоконденсатного месторождения (рис. 3).

Применение предлагаемого способа позволяет повысить эффективность разработки многопластового месторождения за счёт увеличения уровней добычи газа и сокращения продолжительности периода разработки месторождения в результате опережающего ввода в разработку пластов Т и К2 с общей газосборной сетью.

Стоит отметить, что для получения положительного экономического эффекта ввиду существенных капитальных затрат на приобретение МКУ реализация данного способа должна обеспечить соответствующую дополнительную добычу газа.

В качестве альтернативного метода реализации одновременной разработки высокопотенциальных и низкопотенциальных объектов возможно также широкое использование газоструйных аппратов.

Газоструйными аппаратами (ГА) называются устройства, рабочим агентом которых является газ и в которых осуществляется передача кинетической энергии одного потока другому путем непосредственного контакта с образованием смешанного потока [17-20].

На рис. 4 представлена принципиальная технологическая схема эжекторной установки снижения устьевого давления газовых скважин, предложенная в работах [17-19].

За счет разрежения давления, создаваемого на выходе из сопла ГА при истечении через него газа высокого давления $\left(Q_{\mathrm{p}}, P_{\mathrm{p}}\right)$, происходит снижение давления на приеме $\Gamma A\left(Q_{\text {пр }}, P_{\text {пр }}\right)$, в нашем случае устьевого давления низконапорной газовой скважины. Далее в камере смешения ГА происходит смешение продукций участвующих в процессе скважин и восстановление давления до значения линейного давления в системе сбора $\left(P_{\mathrm{c}}=P_{\text {лин }}\right)$.

Таким образом, ГА выполняет роль компрессора низконапорного газа, используя для этого потенциал скважин с высоким устьевым давлением. Эффективность данного метода подтверждена 


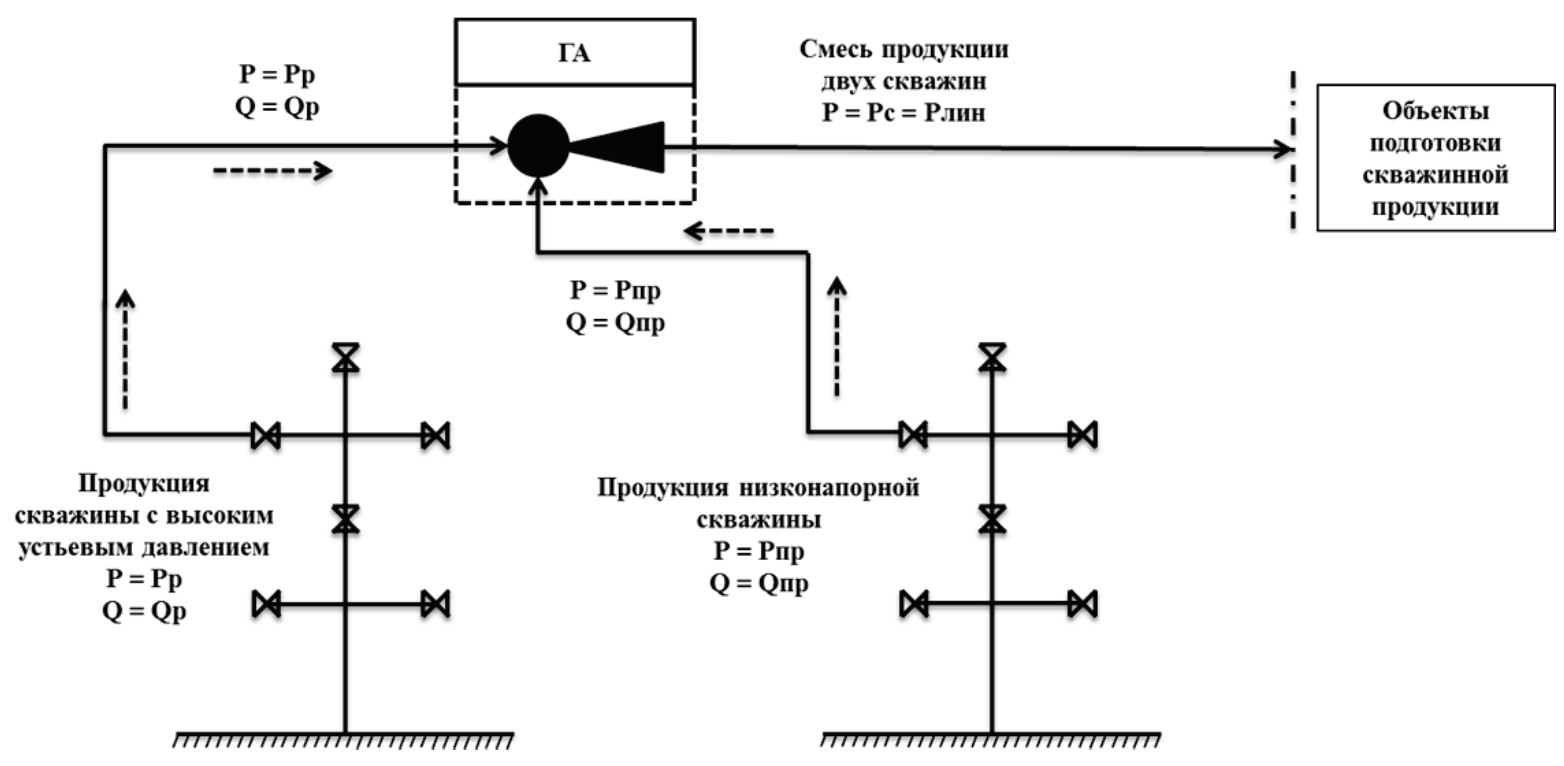

Рис. 4. Приниипиальная технологическая схема эжекторной установки снижения устьевого давления газовых скважин

Fig. 4. Principal technological scheme of an ejector unit for reducing wellhead pressure of gas wells

опытно-промышленными испытаниями. Опыт реализации технологии в 000 «РН-Пурнефтегаз» представлен в работе [17]. Стоит отметить, комбинирование представленных методов позволит усовершенствовать представленные схемы и снизить капитальные затраты на их реализацию.

Применение комплексных решений для повышения эффективности разработки газоконденсатных группы пластов БП Губкинского месторождения

Проанализируем влияние представленных комплексных технологических решений на эффективность разработки группы пластов БП Губкинского месторождения. Для оценки эффективности были произведены два прогнозных расчета: по базовому варианту и варианту с применением комплексных решений на выбывающих в бездействие скважинах.

Базовый вариант предполагает выбытие ряда газовых скважин в бездействие при невозможности их дальнейшей эксплуатации фонтанным способом и последующую довыработку запасов оставшимися скважинами. Вариант с применением комплексных решений предусматривает дальнейшую эксплуатацию всех скважин, что позволит обеспечить выработку запасов в более короткий период, тем самым повысить эффективность разработки месторождения. Динамика уровней добычи и динамика отборов извлекаемых запасов (ОИЗ) представлены на рис. 5 и 6 соответственно.

Расчет прогнозных вариантов производен аналитическим методом, приведем основные используемые формулы. Динамика пластовых давлений определена на основе уравнения материального баланса [2]. Расчет пластового давления и технологических параметров работы скважин осуществлялся с использованием метода последовательной сме- ны стационарных состояний. Дебит газа добывающих скважин вычислялся по двучленной формуле притока:

$$
P_{\text {пл }}^{2}-P_{\text {заб }}^{2}=A q_{\Gamma}+B q_{\Gamma}^{2},
$$

где $A, B$ - коэффициенты фильтрационного сопротивления, МПа 2 ссут/тыс. $\mathrm{M}^{3}$ и $\left(\mathrm{MПа}^{2} \cdot \text { сут/тыс. } \mathrm{M}^{3}\right)^{2}$; $P_{\text {пл }}$ - пластовое давление, МПа; $P_{\text {заб }}$ - забойное давление, МПа; $q_{\mathrm{r}}$ - дебит газа, тыс. $\mathrm{M}^{3} /$ сут.

Определение параметров работающих скважин производилось по формуле Г.А. Адамова [2]:

$$
P_{\text {заб }}^{2}-P_{\text {у }}^{2} e^{2 \chi}=\psi q_{\Gamma}^{2},
$$

где $P_{\text {y }}$ - устьевое давление, МПа; $\psi$ - вспомогательная функция; $\chi$ - показатель, определяемый по формуле:

$$
\chi=\frac{0,03415 \rho_{\text {отн }} H}{Z_{\mathrm{cp}} T_{\mathrm{cp}}},
$$

где $\rho_{\text {отн }}-$ относительная плотность газа, д. ед.; $H$ гипсометрическая отметка глубины интервалов перфорации, м; $Z_{\text {ср }}$ - средний коэффициент сверхсжимаемости, д. ед.; $T_{\text {ср }}$ - средняя по стволу скважины температура, ${ }^{\circ} \mathrm{K}$.

Значение вспомогательной функции $\psi$ :

$$
\psi=1324 \lambda \frac{Z_{\mathrm{cp}}^{2} T_{\mathrm{cp}}^{2}}{d_{\mathrm{BH}}^{5}}\left(e^{2 \chi}-1\right) q_{\mathrm{r}}^{2},
$$

где $\lambda$ - безразмерный коэффициент гидравлического сопротивления; $d_{\text {вн }}$ - внутренний диаметр насосно-компрессорных труб, мм.

В качестве ограничивающего критерия фонтанирования скважины принята минимальная скорость потока на забое скважины, необходимая для выноса жидкости, рассчитанная по формуле А.А. Точигина 

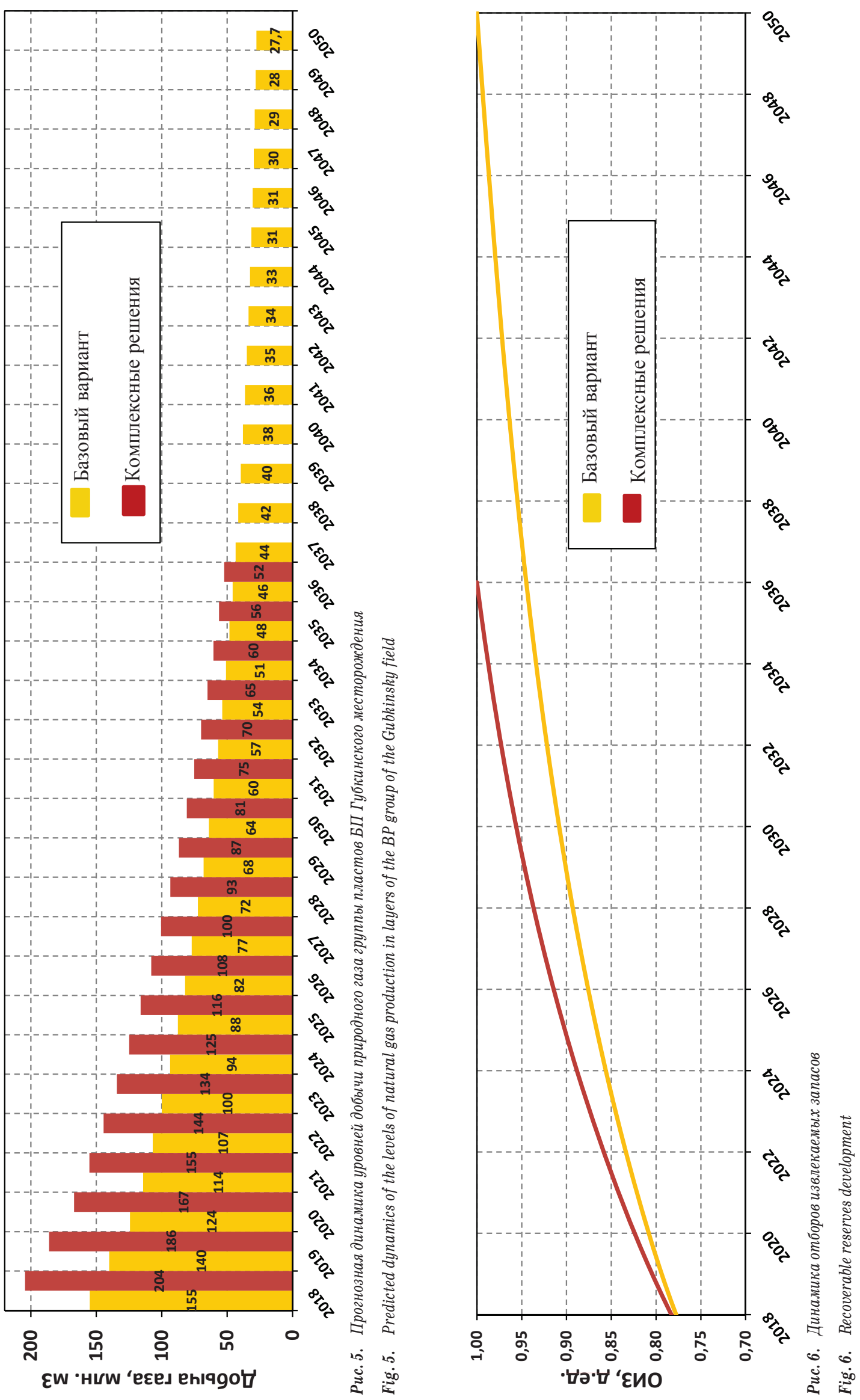


$$
v_{\min }=3,3\left(\frac{9,8 \theta \rho_{\varkappa}^{2}}{\rho_{\mathrm{r}}^{2}\left(\rho_{ж}-\rho_{\mathrm{r}}\right.}\right)^{0,25}
$$

где $v_{\min }$ - минимальная скорость на забое для выноса жидкости в м/с; $\rho_{\text {ж }}$ - плотность жидкой фазы, $\kappa г / \mathrm{M}^{3} ; \rho_{\text {г }}-$ плотность газовой фазы в пластовых условиях, кг $/ \mathrm{M}^{3} ; \theta$ - поверхностное натяжение жидкости, $\mathrm{H} / \mathrm{M}$.

\section{Оценка экономической эффективности комплексных решений}

Прогнозная оценка экономической эффективности применения МКУ производилась на примере куста газовых скважин № 1 Губкинского месторождения, скважины 1, 2, 3 которого находятся в бездействии по причине прекращения фонтанирования. Вывод скважин из бездействия предусматривается внедрением МКУ. Капитальные затраты 150 млн р., NPV проекта 125 млн р.

Оценка экономической эффективности применения ГА выполнена на основе проведения опытно-промышленных испытаний двух газовых скважин 4 и 5 (высоконапорной и низконапорной) куста 2 Губкинского месторождения. По результатам испытаний, скважина 5 выведена из бездействия. NPV проекта составит 31,5 млн р.

\section{СПИСОК ЛИТЕРАТУРЫ}

1. Коротаев Ю.П. Эксплуатация газовых месторождений. - М.: Недра, 1975. - 415 с.

2. Закиров С.Н., Лапук Б.Б. Проектирование и разработка газовых месторождений. - М.: Недра, 1974. - 370 с.

3. Стрижов И.Н., Ходанович И.Е. Добыча газа. - М.; Ижевск: Институт компьютерных исследований, 2003. - 376 с.

4. Закиров С.Н. Разработка газовых, газоконденсатных и нефтегазоконденсатных месторождений. - М.: Струна, 1998. $628 \mathrm{c.}$

5. Способ разработки многопластовых газовых месторождений: пат. 2377396 Рос. Федерация: 2008137698/03; заявл. 19.09.2008; опубл. 27.12.2009, Бюл. № 36. - 2 с.

6. Анализ мирового опыта по освоению трудноизвлекаемых запасов газа и составление плана исследовательских и опытно-промышленных работ для освоения Туронских газовых залежей. Информационный отчет / Рук. темы С.М. Бикбулатов. - Уфа, 000 «РН-УфаНИПИнефть», 2014. - 308 с.

7. Boussa M., Hebbal H. Optimizing production gas wells by using a dual completion // Canadian International Petroleum Conference. - Calgary, Canada, 2006. - P. 1-15.

8. Methods to improve the efficiency of development of a multi-layer offshore gas condensate field: Thien Ung case study / A. Lubnin, E. Yudin, G. Sansiev, T. Karimov, V. Bondarenko // 187865MS SPE Conference Paper. - Moscow, Russia, 2017. - P. 1-10.

9. Lea J.F., Nickens H.V., Wells M.R. Gas well deliquification. USA: Gulf Professional Publ., 2008. - 588 p.

10. Lea J.F., Tighe R.E. Gas well operation with liquid production // Production Operation Symposium. - Oklahoma City, OK, February 27 - March 1, 1983. - P. 1-13.

11. Балашова В.Д., Лаптев Е.М., Ковальчук 0.Ю. Оптимизация работы газосборной сети на поздней стадии разработки // Газовая промышленность. - 2014. - № 708. - С. 53-55.

12. Перспективы применения распределенного компримирования в промысловых системах добычи газа / М.А. Воронцов,

\section{Заключение}

Применение модульных компрессорных установок и газоструйных аппаратов в варианте одновременной разработки существенно отличающихся по ресурсно-энергетическому потенциалу и/или фильтрационно-емкостным свойствам эксплуатационных объектов многопластового месторождения с общей газосборной сетью, рассматриваемом в качестве альтернативного варианту поочерёдного ввода в разработку этих объектов, позволяет повысить техникоэкономическую эффективность разработки объектов месторождения за счёт увеличения уровней добычи газа и сокращения срока выработки запасов.

Технология применения газоструйных аппаратов апробирована при проведении опытно-промышленных испытаний на группе газовых скважин Губкинского месторождения. Использование газоструйных аппаратов позволило произвести опережающий ввод в разработку высокопотенциального пласта Губкинского месторождения при одновременном обеспечении устойчивых технологических режимов работы действующих низконапорных газовых скважин, вскрывших низкопотенциальные залежи. Целесообразность применения технологии комплексных решений для добычи газа и конденсата может быть рассмотрена на любой стадии разработки месторождений.

А.А. Ротов, И.В. Марущенко, Е.В. Лаптев // Вести газовой науки. - 2014. - № 4 (20). - С. 164-173.

13. Natural gas saver with separator and compressor. Patent U.S., no. $168,841,1971$.

14. Libson T.N., Henry J.T. Case histories: identification of and remedial action for liquid loading in gas wells-intermediate shelf gas play // Journal of Petroleum Technology. - April 1980. V. 32 (4) - P. 685-693.

15. A new look at predicting gas well liquid load-up / S.B. Coleman, H.B. Clay, D.V. McCurdy, H.N. Lea // Journal of Petroleum Technology. - March 1991. - V. 43 (3) - P. 329-332.

16. Harms L.K. Installing low-cost, low-pressure wellhead compression on tight Lobo Wilcox wells in South Texas: a case history // 2004 SPE Annual Technical Conference and Exhibition. - Houston, TX, September 26-29, 2004. - P. 1-16

17. Обеспечение устойчивых технологических режимов эксплуатации газовых скважин на поздней стадии разработки месторождения с применением устьевых газоструйных аппаратов / А.И. Пономарев, В.С. Вербицкий, А.Э. Федоров, А.А. Ибатулин // Вести газовой науки. - 2018. - № 1. - С. 171-180.

18. Федоров А.Э., Вербицкий В.С., Горидько К.А. Экспериментальные исследования и анализ характеристик работы газоструйных аппаратов для добычи нефти и газа из скважин с осложненными условиями эксплуатации // Российская нефтегазовая техническая конференция и выставка SPE. - М., 2016. - SPE-181956-RU.

19. Федоров А.Э., Ибатулин А.А. Повышение эффективности эксплуатации газовых скважин с применением устьевых газоструйных аппаратов // Статья SPE 191733, подготовленная для презентации на Российской нефтегазовой технической конференции и выставке SPE. - M., 2018. - SPE-191733-18RPTC-RU.

20. Beg N., Sarshar S. Surface Jet Pumps (SJPs) for enhanced oil \& gas production. - United Kingdom: Caltec Ltd, 2014. - 127 p.

Поступила: 29.11.2018 г. 


\section{Информация об авторах}

Пономарёв А.И., доктор технических наук, профессор, заведующий кафедрой разработки и эксплуатации газовых и нефтегазоконденсатных месторождений Уфимского государственного нефтяного технического университета.

Ситдиков P.Ф., начальник управления геологии и лицензирования 000 «Харампурнефтегаз».

Ибатулин A.A., аспирант кафедры разработки и эксплуатации газовых и нефтегазоконденсатных месторождений Уфимского государственного нефтяного технического университета; ведущий специалист управления по разработке месторождений 000 «РН-Пурнефтегаз».

Федоров А.Э., аспирант кафедры разработки и эксплуатации нефтяных месторождений Российский государственный университет нефти и газа (национальный исследовательский университет) им. И.М. Губкина; начальник сектора управления повышения производительности резервуаров и геолого-технических мероприятий 000 «РН-Пурнефтегаз» .

Муслимов Б.ШІ, начальник отдела разработки нефтегазовых залежей 000 «НН-УфаНИПИнефть». 
UDC 622.276

\title{
COMPLEX SOLUTIONS TO INCREASE THE EFFICIENCY OF DEVELOPMENT OF MULTI-LAYER GAS AND GAS-CONDENSATE FIELDS
}

\author{
Aleksandr I. Ponomarev', \\ pnmrv@mail.ru \\ Rustam F. Sitdikov², \\ SitdikovRF@kchn.ru
}

Artur A. Ibatulin ${ }^{1,3}$,

AAlbatulin@purneftegaz.ru

\author{
Aleksey E. Fedorov ${ }^{4,3}$, \\ AEFedorov@purneftegaz.ru \\ Bulat Sh. Muslimov ${ }^{5}$, \\ MuslimovBS@ufanipi.ru \\ ${ }^{1}$ Ufa State Petroleum Technological University, \\ 1, Kosmonavtov street, Ufa, 450062, Russia. \\ 2 LLC Kharampurneftegaz, \\ 3, territory panel 1, Gubkinsky, 629830, Russia. \\ ${ }^{3}$ LLC Rosneft-Purneftegaz, \\ 3, microdistrict 10, Gubkinsky, 629830, Russia. \\ ${ }^{4}$ National University of Oil and Gas "Gubkin University», \\ 65, Leninsky avenue, Moscow, 119991, Russia. \\ ${ }^{5}$ LLC Rosneft-UfaNIPIneft, \\ 12, Sochinskaya street, Ufa, 450103, Russia.
}

Relevance. To reduce capital costs and time of developing gas reserves and condensate from a multilayer gas condensate field, an urgent task is to justify the technology of simultaneous development of different by potential and/or filtration-capacitive properties reservoirs with gas supply to one gas gathering network. The solution of this problem is relevant both at the design stage and at the mature stage of field development in the mode of depletion of reservoir energy. Under the conditions of a sharp difference in the resource-energy potential and reservoir properties of the developing reservoirs, low-pressure wells with a certain backpressure in the gas gathering system stop flowing and are transferred to an inactive fund until the linear pressure decreases to the required level.

The aim of the research is the rationale of integrated technological solutions aimed at improving the development of multilayer gas and gas condensate fields with a single gas gathering system.

Objects: multilayer gas and gas condensate fields, which contain in their geological section the fragmented and different in terms of resource and energy potential and filtration-capacitive properties selected operational objects.

Methods: analysis of the current state of developing gas production facilities of the Gubkinskoe field, analytical calculations of technological modes of operation of low-pressure wells, conducting pilot tests at gas wells of the Gubkinskoe field, a feasibility study of the results of applying the proposed technologies.

Results. The authors have analyzed the current state of the Gubkinskoe field, characterized by a high differentiation of the current reservoir pressures in the reservoirs. Integrated solutions were proposed to ensure joint development of production facilities with gas supply to the general gas-gathering network, ensuring stable operation modes of the wells and based on controlling wellhead pressure by various technical devices. The technical and economic assessment of the impact of the presented complex technological solutions on the development efficiency of the reservoirs of the lower cretaceous deposits of the Gubkinskoe field was made.

Key words:

Development of multilayer gas fields, modular compressor stations, gas-jet devices, multi layered reservoir, pilot-scale tests.

\section{REFERENCES}

1. Korotaev Yu.P. Ekspluatatsiya gazovykh mestorozhdeniy [Exploitation of gas fields]. Moscow, Nedra Publ., 1975. 415 p.

2. Zakirov S.N., Lapuk B.B. Proektirovanie i razrabotka gazovykh mestorozhdeniy [Design and development of gas fields]. Moscow, Nedra Publ., 1974.370 p.

3. Strizhov I.N., Khodanovich I.E. Dobycha gaza [Gas production]. Moscow; Izhevsk, Institute of complex researches Publ., 2003. 367 p.
4. Zakirov S.N. Razrabotka gazovykh, gazokondensatnykh i neftegazokondensatnykh mestorozhdeniy [Development of gas, gas condensate and oil and gas condensate fields]. Moscow, Struna Publ., $1998.628 \mathrm{p}$.

5. Gafarov N.A., Gordeev V.N., Menshikov S.N. Sposob razrabotki mnogoplastovykh gazovykh mestorozhdeniy [Method of development of multilayer gas fields]. Patent RF, no. 2008137698/03, 2009. 
6. Analiz mirovogo opyta po osvoeniyu trudnoizvlekayemykh zapasov gaza $i$ sostavlenie plana issledovatelskikh $i$ opytno-pro myshlennykh rabot dlya osvoeniya Turonskikh gazovykh zalezhey. Informatsionny otche. [Analysis of world experience in development of hard to recover gas reserves and drawing up a plan of research and pilot works for development of Turon gas deposits.]. Ufa, RN-UfaNIPIneft Publ., 2014. 308 p.

7. Boussa M., Hebbal H. Optimizing production gas wells by using a dual completion. Canadian International Petroleum Conference. Calgary, Canada, 2006. pp. 1-15.

8. Lubnin A., Yudin E., Sansiev G., Karimov T., Bondarenko V. Methods to improve the efficiency of development of a multi-layer offshore gas condensate field: Thien Ung case study. 187865 MS SPE Conference Paper. Moscow, Russia, 2017. pp. 1-10.

9. Lea J.F., Nickens H.V., Wells M.R. Gas well deliquification. USA, Gulf Professional Publ., 2008. 588 p.

10. Lea J.F., Tighe R.E. Gas well operation with liquid production. Production Operation Symposium. Oklahoma City, OK, February 27 - March 1, 1983. pp. 1-13

11. Balashova V.D., Laptev E.M., Kovalchuk 0.Yu. Optimizatsiya raboty gazosbornoy seti na pozdney stadii razrabotki [0ptimization of gas gathering pipeline system at the late stage of development]. Gas industry, 2014, no. 708, pp. 53-55.

12. Vorontsov M.A., Rotov A.A., Marushchenko I.V., Laptev E.V. Prospects of use of distributed compression in field gas production systems. News of gas science, 2014, no. 4 (20), pp. 164-173. In Rus.

13. Tipton D.F., Jeffers L.R. Natural gas saver with separator and compressor. Patent U.S., no. 168,841, 1971.
14. Libson T.N., Henry J.T. Case histories: identification of and remedial action for liquid loading in gas wells-intermediate shelf gas play. Journal of Petroleum Technology, April 1980, vol. 32 (4), pp. 685-693.

15. Coleman S.B., Clay H.B., McCurdy D.V., Lea H.N. A new look at predicting gas well liquid load-up. Journal of Petroleum Technology, March 1991, vol. 43 (3), pp. 329-332.

16. Harms L.K. Installing low-cost, low-pressure wellhead compression on Tight Lobo Wilcox wells in South Texas: a case history. 004 SPE Annual Technical Conference and Exhibition. Houston, TX, September 26-29, 2004. pp. 1-16.

17. Ponomarev A.I., Verbitsky V.S., Fedorov A.E., Ibatulin A.A. Provision of stable technological modes of operation of gas wells at a late stage of field development using wellhead gas-jet apparatuses. News of gas science, 2018, no. 1, pp. 171-180. In Rus.

18. Fedorov A.E., Verbitsky V.S., Goridko K.A. Experimental studies and analysis of gas-jet device's operation characteristics for oil and gas production in abnormal operating conditions. SPE Russian Petroleum Technology Conference. Moscow, 2016. SPE181956-MS.

19. Fedorov A.E., Ibatulin A.A. Increasing of operation efficiency of low pressure gas wells by using of gas-jet device's. SPE Russian Petroleum Technology Conference. Moscow, 2018. SPE191733-18RPTC-MS.

20. Beg N., Sarshar S. Surface Jet Pumps (SJPs) for Enhanced Oil \& Gas Production. United Kingdom, Caltec Ltd, 2014. 127 p.

Received: 29 November 2018.

\section{Information about the authors}

Aleksandr I. Ponomarev, Dr. Sc., professor, head of development and exploitation of gas and oil-gas-condensate fields department, Ufa State Petroleum Technological University.

Rustam F . Sitdikov, head of the Geology and Licensing Department, LLC Kharampurneftegaz.

Artur A. Ibatulin, leading specialist of Fields Development Department, LLC Rosneft-Purneftegaz, postgraduate student, Ufa State Petroleum Technological University.

Aleksey E. Fedorov, head of section, LLC Rosneft-Purneftegaz, postgraduate student, Petroleum Reservoir Engineering Department of Gubkin Russian State University of Oil and Gas (National Research University).

Bulat Sh. Muslimov, head of Oil and Gas Fields Department, LLC Rosneft-UfaNIPIneft. 